\title{
Sewage Treatment System Planning for Dianchi Urban Wetland Park in Kunming
}

\author{
Yan-Sheng $\mathrm{Wu}^{1}$, Yan $\mathrm{Li}^{2,}{ }^{*}$, Xiong $\mathrm{Gao}^{3}$, Jie $\mathrm{Pan}^{3}$, ning Wang ${ }^{3}$, Yong-Wei Cheng ${ }^{3}$, Cong-Gao Yang ${ }^{4}$, Ya-Chao Yang ${ }^{5}$ \\ ${ }^{1}$ Department of Infrastructure Construction, Kunming Metallurgy College, Kunming 650033, Yunnan, China \\ ${ }^{2}$ Faculty of Architecture Engineering, Kunming Metallurgy College, Kunming 650033, Yunnan, China \\ ${ }^{3}$ Faculty of Environmental Engineering, Kunming Metallurgy College, Kunming 650033, Yunnan, China \\ ${ }^{4}$ KunmingApprisal Center for Ecological Environmental \& Engineering, Kunming 650023, Yunnan, China \\ ${ }^{5}$ Yunnan Provincial Institute of Urban and Rural Planning and Design, Kunming 650021, Yunnan, China
}

\begin{abstract}
Dianchi Lake urban wetland park in Kunming is an important component of Dianchi lakeside wetlands, it is of great significance to the urban development and ecological protection of Kunming. To solve the problem of non-point source pollution of Dianchi Lake basin, the Dianchi Lake Pan-Asian International Urban Wetland Park is taken as an example, the rapid artificial infiltration treatment system and the comprehensive constructed wetland treatment system were designed for Dianchi Lake urban wetland park, and various design parameters and its influencing factors have been analyzed. After the deep treatment by the treatment system, the water quality reached the standards of landscape water. The planning of water system for Dianchi Lake urban wetland park provides a reference for designing plateau lake urban wetland parks.
\end{abstract}

\section{Introduction}

Kunming Dianchi International Urban Wetland Park is located in the Dianchi National Tourism and Resort Zone in the south of Kunming, next to Dianchi Lake.The wetland park is an important part of the lakeshore wetland in Dianchi Lake. The construction of the wetland system will build a protective barrier on the northern shore of Dianchi Lake, strengthen the treatment of point and nonpoint source pollution in the vicinity of the wetland park, reduce the pollution load into Dianchi Lake, and improve drainage. The quality of the water entering the Dianchi Lake's offshore waters promotes the restoration of the lakeshore ecosystem of Dianchi Lake. The construction of the wetland park and the sewage treatment around the lake constitute a complete pollution control system.

The pollution control system has played a role in demonstration of ecological education for the construction of surrounding wetlands and the treatment of Dianchi Lake, and has become an important support for the pollution prevention project of Dianchi Lake.

Kunming Dianchi Urban Wetland Park has a total construction area of $163.3 \mathrm{hm}^{2}$, an artificial rapid infiltration system of $3560 \mathrm{~m}^{2}$, and a composite artificial wetland system of $13.33 \mathrm{hm}^{2}$. It mainly treats part of the river water of the Baoxiang River and the domestic sewage in the park. Restoring and constructing natural wetland $23 \mathrm{hm}^{2}$ and constructing protective forest belt $35.78 \mathrm{hm}^{2}$, the purpose is to enhance landscape function and cut off pollution processing unit. Wetland research center and demonstration base $4 \mathrm{hm}^{2}$, on the one hand, as a wetland botanical garden, showing the diversity of species in the Dianchi Lake Basin and improving the landscape function.

\section{Materials and Methods}

\subsection{Objectives of water system planning}

Wetland engineering dictates that we take advantage of our ever increasing knowledge of ecology and its principles to design a system that will be as close to a natural feature of the landscape as possible and will require a minimum amount of maintenance. This means resisting the ever-present temptation to over-engineer, to channel energies that cannot be channeled, to impose species that the design does not support. We agree with Boule who recommends that the design of wetlands should be kept simple without reliance on complex technological approaches that invite failure: "Simple systems tend to be self-regulating and self-maintaining" .

The main content of the wetland park water system construction:

- Flood control of Baoxiang River.

- Purification and treatment of domestic sewage discharged from the residential areas in the project area.

- Storm water or non-point source pollution control of lower Baoxiang River Basin.

- Establishment an public environmental education for research wetland.

The design should take into account the characteristics of non-rainfall period and rainfall period, and adopt the

*Corresponding author: 28361761@qq.com 
design technology with high treatment efficiency, strong pollution interception ability and favorable water flow stability during rainfall period. According to the topographic and geomorphological characteristics of each part, the corresponding engineering system is designed to minimize the amount of earthwork. The layout of the project should take into account the pollution control effect, ecological effect, landscape effect and capital construction investment to realize the overall optimization of the project.

\subsection{Water quality of inlet and outlet}

The water source is Baoxiang river, the water quality has reached the design specification for wastewater recycling engineering (China National Standard GB50335-2016) (Table 1).

Table 1. Water Quality Indicators for Inlet and Outlet

\begin{tabular}{|c|c|c|}
\hline Parameter & $\begin{array}{c}\text { Water } \\
\text { Quality } \\
\text { Indicators } \\
\text { for Inlet }\end{array}$ & $\begin{array}{c}\text { Water Quality } \\
\text { Indicators for } \\
\text { Outlet } \\
\text { (GB50335- } \\
\text { 2016) }\end{array}$ \\
\hline $\mathrm{PH}$ & $6-9$ & $6-9$ \\
\hline
\end{tabular}

\begin{tabular}{|c|c|c|}
\hline $\mathrm{CODcr} \leq(\mathrm{mg} / \mathrm{L})$ & 120 & 20 \\
\hline $\mathrm{BOD}_{5} \leq(\mathrm{mg} / \mathrm{L})$ & 40 & 6 \\
\hline $\mathrm{SS} \leq(\mathrm{mg} / \mathrm{L})$ & 50 & 10 \\
\hline $\mathrm{NH} 3-\mathrm{N} \leq(\mathrm{mg} / \mathrm{L})$ & 10 & 5 \\
\hline $\mathrm{TP}(\mathrm{mg} / \mathrm{L})$ & 2 & 0.5 \\
\hline
\end{tabular}

\subsection{Sewage treatment process}

The core of the water purification system is to construct an artificial rapid infiltration treatment system and a construct wetland treatment system. The sewage enters the artificial wetland after the artificial rapid infiltration treatment, and the ecologically purified water finally enters the park landscape lake. The Constructed Rapid Infiltration (CRI) system can be applied to both domestic sewage treatment and water purification of polluted rivers. The purification mechanism of the CRI system includes three processes: filtration, biological film, and adsorption.

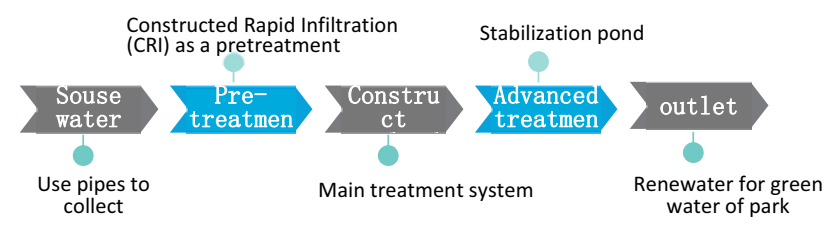

Fig. 1. Flow chart of water system process.

The constructed wetland treatment system is constructed by a combination of surface flow constructed wetlands and horizontal subsurface flow constructed wetlands. The system's water flow operation combines the characteristics of surface flow constructed wetlands and horizontal subsurface flow constructed wetlands. The wetland system saves construction area, which is beneficial for nitrogen and phosphorus removal, and has stable treatment effect and high unit area treatment efficiency.

\subsection{Designing of water purification system}

The CRI treatment system consists of lifting pumps tank and rapid infiltration tank.

Treatment reduce the pollution of the sewage, Biochemical Oxygen Demand(BOD), Chemical oxygen demand(COD), suspended solids(SS), has gone down significantly in infiltration tank.

The composite constructed wetland is composed of sewage collection system, water distribution system, wetland system, stabilization pond .The stabilization pond at the end of constructed wetland, water enters the natural wetland through the stabilization pond and outlet system.

\subsubsection{Sewage collection system}

Collect sewage from kitchen and toilet of park,house drainage enter the sewage treatment station by the main sewage drainage pipe. Baoxiang River water is pumped to the pumping pool.

\subsubsection{Wetland inlet water system}

Inlet water system is important to wetland design and operation,A reasonable and effective design of inlet system effect Water Quality for Outlet,the key is water distribution and the rationality of structure are straight.

\subsubsection{Constructed rapid infiltration}

Constructed rapid infiltration (CRI) system is a new type of sewage biofilm treatmenttechnology, however, a shortcutnitrification-denitrification process presents distinctive advantages, as it saves oxygen, requiresless organic matter, and requires less time for denitrification compared to conventional nitrogenremoval methods.I system is mainly composed of a feeding tank, grill, preliminary sedimentation tank, rapid infiltration tank, and outlet system. The system adopts the dry-wet 
(alternate running of feeding and drying in the CRI system) alternating operation mode and uses natural river sand, coal gangue, natural gravel, etc., to replace natural soil as the filling medium to improve the hydraulic load to 1.0 $1.5 \mathrm{~m} /$ day.

Project design treatment water flow rate $4000.0 \mathrm{~m}^{3} / \mathrm{d}$.

-The hydraulic load cycle (HLC) is $3 \mathrm{~h}$,of which was flooded $1 \mathrm{~h}$,dry $2 \mathrm{~h}$. The flood to dry ratio (FDR) is 0.5 .

-Hydraulic load (HLR): $1.5 \mathrm{~m}^{3} / \mathrm{m}^{2} \cdot \mathrm{d}$.

-Area of the rapid infiltration tank is $2,666.7 \mathrm{~m}^{2}$.

\subsubsection{Constructed wetland}

Due to its anaerobic zone it lacks the carbon sources and the conditions fornitrate retention, and CRI's nitrogen removal performance is very poor.Constructed wetland is used to improve it,wetland consists of surface flow type and subsurface flow type. The structure of surface wetland is simple, costing is low.It works fine in the rain season.Park's surface flow wetland average water depth is $0.4 \mathrm{~m}$, total area is $3.33 \mathrm{hm}^{2}$. The area of the subsurface wetland is $10 \mathrm{hm}^{2}$.

Project design treatment water flow rate $4000.0 \mathrm{~m}^{3} / \mathrm{d}$.

-Hydraulic load (HLR): $0.5 \mathrm{~m}^{3} / \mathrm{m}^{2} \cdot \mathrm{d}$.

-Average slope gradient is 3\%0 5\%

-Hydraulic retention time is $8.1 \mathrm{~d}$.

-Horizontal flow velocity is $0.20 \mathrm{~m} / \mathrm{s}$

\subsubsection{Stabilization pond}

The stabilization pond was used for drainage water after constructed wetland,in the plant bed, Zizania caduciflora and Phragites austrails were planted. The depth of pond is $0.5 \mathrm{~m}$, surface area $6,300 \mathrm{~m}^{2}$.The stabilization pond improve the effluent quality of the constructed wetland, and enhance the richness of the park landscape.

\subsubsection{Outlet system}

An overflow weir is set up at the end of stabilization pond, and a water outlet is evenly arranged at an interval of $2 \mathrm{~m}$ at the top of the weir.

\section{Results and Discussion}

The design of constructed wetlands for Dianchi Lake urban wetland park is limited by the geographical environment and the quality of the inlet water. The design takes into account the incoming hydraulic load, the organic load, the form of the wetland structure, the process flow and water distribution, the characteristics of the intel and outlet water, the substrate of the wetland, the type of plants planted in the wetland and the local climatic conditions. When designing surface flow constructed wetlands for park, the key design parameters to be considered are: hydraulic load, hydraulic slope and bottom slope, hydraulic retention time, width, depth and length, and horizontal flow rate.

The widespread application of constructed wetlands for wastewater treatment requires better engineering design, thus more accurate pollutant removal models are needed. The sewage treatment system of the park is designed based on the above parameters(Fig.2;Fig.3),As an effective tool to control non-point source pollution, constructed wetlands is a new disposal method which is efficient, economical and environmental protection, are increasingly recognized in Dianchi Lake area.

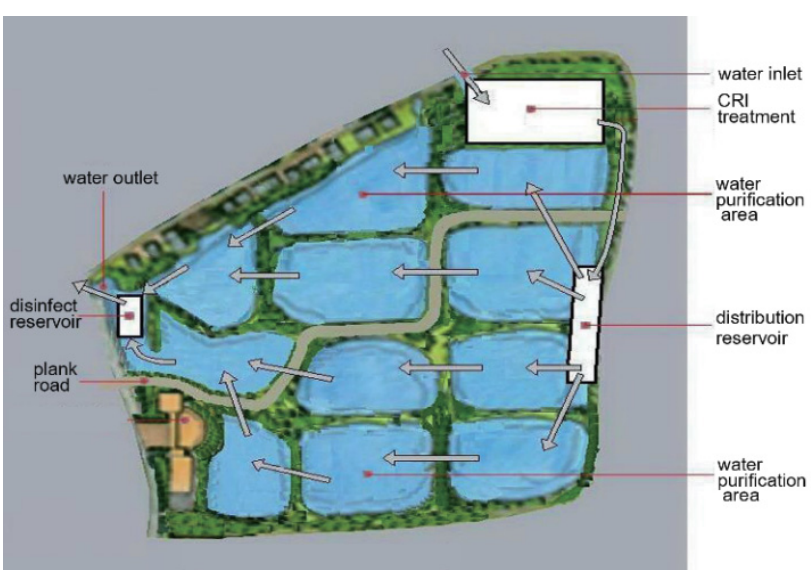

Fig. 2. Plan of sewage treatment system.

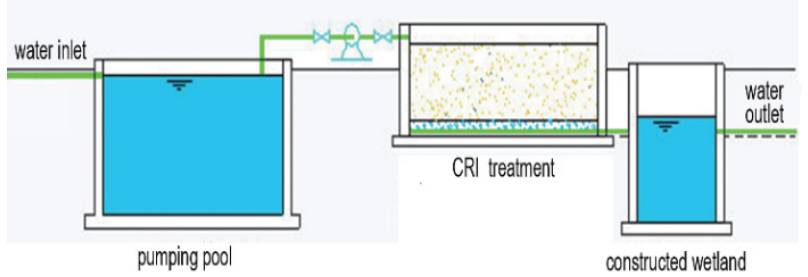

Fig. 3. Basic flow chart of artificial rapid infiltration system.

\section{Conclusions}

The planning of the park is important for the protection and rational utilization of wetland resources.The complexity and comprehensiveness of wetland park planning and design are due to the complexity and diversity of wetland.

The planning of wetland park must be based on local conditions, such as climate, hydrology, water quality, geology and other conditions, and combined with the regional economic and cultural background.The water purification system of Dianchi Lake urban wetland park can provide useful reference experience for the planning and construction of similar wetland parks in China.

\section{Acknowledgments}

This work is supported by Science Research Foundation of Yunnan Province Education Department (No.2019J0887 、 No.2020J0773)、 Science Research Foundation of Yunnan Province Science and Technology Department (No.2018FD065) and Science Research Foundation of Kunming Metallurgy College (No.2019xjzk11). 


\section{References}

1. Dittrich Ernő, Salamon-Albert Éva,Somfai Dávid, Dolgos-Kovács Anita,Kiss Tibor. Transpiration effect of Tufted sedge for a horizontal subsurface flow constructed wetland.[J]. Water science and technology: a journal of the International Association on Water Pollution Research,2019,79(10).

2. Lim Dohun, Lee Yoonjin. Assessment of Non-Point Source Pollutant Loads and Priority Management Areas using an HSPF Model in Sejong City, South Korea[J]. Journal of Environmental Science International, 2017,26(8).

3. Choi Kwangsoon, Kim Sea Won,Kim Dong Sup,Lee Yosang. Operating Status and Improvement Plans of Ten Wetlands Constructed in Dam Reservoirs in Korea[J]. Journal of Wetlands Research,2014,16(3).

4. Lee Jung Min, Hyun Kyoung Hak, Lee Yun Sang, Kim Jung Gon, Park Yong Boo, Choi Jong Soo. Analysis of Water Cycle Effect by Plan of LIDdecentralized Rainwater Management Using SWMM-LID Model in a Low-carbon Green Village[J]. LHI Journal of Land, Housing, and Urban Affairs, 2011,2(4).

5. Liu Nana. Wetland design in sponge city construction based on ArcGIS and Internet of Things system[J]. Microprocessors and Microsystems,2020(prepublish).

6. Edith Martinez - Guerra,Umesh Ghimire,Hariteja Nandimandalam,Anna Norris,Veera Gnaneswar Gude. Wetlands for environmental protection[J]. Water Environment Research,2020,92(10).

7. Edith Martinez - Guerra,Umesh Ghimire,Hariteja Nandimandalam,Anna Norris,Veera Gnaneswar Gude. Wetlands for environmental protection[J]. Water Environment Research,2020,92(10).

8. Martinez Guerra Edith, Ghimire Umesh, Nandimandalam Hariteja, Norris Anna, Gude Veera Gnaneswar. Wetlands for environmental protection.[J]. Water environment research: a research publication of the Water Environment Federation, 2020.

9. Franciszek Bydałek,S. Myszograj. Safe surface concept in vertical flow constructed wetland design to mitigate infection hazard[J]. Journal of Environmental Science and Health, Part A,2019,54(3).

10. Martinez-Guerra Edith, Ghimire Umesh, Nandimandalam Hariteja, Norris Anna, Gude Veera Gnaneswar. Wetlands for Environmental Protection. [J]. Water environment research: a research publication of the Water Environment Federation, 2020.

11. Zhen Ma,Yuanlai Cui,Changqiang Guo,Yufeng Luo,Di Wan,Linhua Ma,Yonghong Shu,Fangping Liu. Consistency analysis of the optimal combination of free water surface constructed wetland design optimization over different seasons[J]. Ecological Engineering,2020,155.

12. Seung Won Lee,Joon Ha Kim,Sung Min Cha.
Analysis of the relation between pollutant loading and water depth flowrate changes in a constructed wetland for agricultural nonpoint source pollution management[J]. Ecological Engineering,2020,152.

13. Huma Ilyas,Eric D. van Hullebusch. Performance Comparison of Different Constructed Wetlands Designs for the Removal of Personal Care Products[J]. International Journal of Environmental Research and Public Health,2020,17(9).

14. Qinglin Fang, Wenlai Xu, Zhijiao Yan, Lei Qian.Effect of Potassium Chlorate on the Treatment of Domestic Sewage by Achieving Shortcut Nitrification in a Constructed Rapid Infiltration System[J].Int. J. Environ. Res. Public Health 2018, 15, 670 ;

15. Maria A. Economopoulou and Vassilios A. Tsihrintzis $[\mathrm{J}]$. Water Resources Management 18: 541-565, 2004.

16. WU Yan sheng.The Study on Design Parameters of Integrated Constructed Wetland System[J].Yunnan Metallurgy sum252: 83-85,2015

17. WU Yan sheng.The Study on Using CRI to improve constructed wetland system stoppage[J].Journal of Kunming Metallurgy College.30:84-88,2014 